\title{
Studi Identifikasi Jenis-Jenis Pantun dalam Masyarakat Kaur Provinsi Bengkulu
}

\author{
Dedi Apriansah \\ Universitas Bengkulu \\ dhedy.afsh.da@gmail.com
}

\author{
Abdul Muktadir \\ Universitas Bengkulu \\ Herman Lusa \\ Universitas Bengkulu
}

\begin{abstract}
This study aims to identify the Kaur language rhymes in accordance with the types of rhymes in the Kaur community of Bengkulu Province. The approach and type of research used are qualitative survey. The research location is Pengubaian Village, Gedung Sako II Village and Air Dingin Village, Bintuhan city, Kaur Selatan District, Kaur District. Subjects used as informants in the research are the chief of Kaur customary institutions in the village of Air Dingin, Community leaders Pengubaian villagers, and community leaders Gedung Sako II Village. Data collection techniques used in this study are interviews to informants and documentation. The document obtained were analyzed by data reduction, data display, and conclusion. Validity of document using extension of observation, improvement of persistence, triangulation of source and member check. Research results collected fifty-two rhyme Kaur language rhymes contained in the three villages. Fourteen rhymes from the village of Pengubaian, eighteen rhymes from the village of Gedung Sako II and twenty rhymes from the village of Air Dingin. Based on the results of identification can be concluded that, from fifty-two Kaur language rhymes, which is adapted to the types of rhymes obtained, namely: a puzzle rhymes, nine advice rhymes, eight affection rhymes, three spirit rhymes, two custom rhymes, Three religious rhymes, eight witty rhymes, eleven figurative rhymes, six romance rhymes and one proverb rhymes.
\end{abstract}

Keywords: The Kaur language rhymes, Kinds of rhymes, Kaur People

\section{Pendahuluan}

Keberadaan pantun sekarang ini sangat mengkhawatirkan karena kurangnya minat generasi muda untuk mempelajarinya. Bahkan saat ini jarang ditemui orang yang pandai berpantun. Hal ini terjadi karena pantun kurang diajarkan bahkan tidak diajarkan di sekolah-sekolah karena guru 
kurang mampu untuk mengajarkan pantun dengan baik, sehingga siswa tidak tertarik dan merasa bosan dengan pembelajaran pantun. Pantun kurang diajarkan dengan optimal di sekolah sejalan dengan pendapat Fatimah (2014: 3-4), bahwa pembelajaran sastra terutama pantun tidak mendapatkan perhatian seperti materi pembelajaran Bahasa Indonesia yang lainnya karena pembelajaran apresiasi sastra pantun sangat jarang ada di dalam soal ulangan.

Pada saat ini pantun bahasa Kaur sudah jarang ditemukan karena masyarakat Kaur tidak menggunakan pantun ini dalam berkomunikasi ataupun acara adat pernikahan. Hal ini dipengaruhi oleh zaman globalisasi dimana masyarakat lebih tertarik menggunakan budaya luar dibandingkan dengan budaya lokal yang ada. Seperti dalam acara pesta pernikahan masyarakat Kaur lebih menyukai hiburan organ tunggal dibandingan dengan budaya daerah mereka, seperti mainangan, sede'rean dan berbalas pantun. Menurut Herimanto (2014 : 89), dampak negatif dari globaliasi adalah masuknya nilai budaya luar yang akan menghilangkan nilai-nilai tradisi suatu bangsa dan identitas suatu bangsa.

Berdasarkan kenyatan di lapangan pantun bahasa Kaur tidak dibukukan secara khusus dan jarang ditemukan masyarakat Kaur menggunakan seni berpantun dalam kegiatan adat atau berkomunikasi. Padahal dahulu pantun sangat banyak dan terkenal di masyarakat. Maka dari itu peneliti ingin mengumpulkan dan mengidentifikasi pantun-pantun bahasa Kaur sesuai dengan jenis-jenis pantun agar dapat diketahui jenis-jenis pantun yang terdapat di masyarakat Kaur.Berdasarkan permasalahan tersebut maka peneliti tertarik melakukan penelitian tentang "Studi Identifikasi JenisJenis Pantun dalam Masyarakat Kaur Provinsi Bengkulu".

Pantun adalah salah satu jenis puisi lama yang terdiri dari empat baris. Menurut Purwandari (2015: 167), "pantun adalah puisi yang bercirikan bersajak a-b-a-b, tiap bait 4 baris, tiap baris terdiri atas 8-12 suku kata, 2 baris awal sebagai sampiran, 2 baris berikutnya sebagai isi".Pantun sudah digunakan oleh masyarakat sejak zaman dahulu. Menurut Wahyuni (2014: 140), sejarah perkembangan pantun lama dimulai pada zaman dahulu ketika masyarakat Melayu senang sekali berpantun. Pantun lama banyak digunakan di setiap acara. Pantun lama semakin luas perkembangannya pada saat banyak digunakan oleh pemuda-pemudi yang saling berkenalan.

Pantun merupakan sastra lama yang bisa digunakan untuk anak-anak, remaja dan orang tua. Jenis-jenis pantun menurut Wahyuni (2014: 152-172), adalahpantun teka-teki, pantun nasihat, pantun kasih sayang, pantun semangat, pantun adat, pantun agama, pantun jenaka, pantun kiasan, pantun percintaan dan pantun peribahasa. Setiap pantun yang dicipta mempunyai fungsi atau kegunaannya sendiri.

Bahasa Kaur adalah bahasa yang dituturkan oleh suku Kaur yang mendiami sepanjang pantai barat daya ekstrim dan lereng gunung provinsi Bengkulu, di kota Bintuhan pulau Sumatra Indonesia. Bahasa Kaur termasuk dalam kelompok rumpun bahasa Melayu Tengah dan termasuk dalam bahasa Malayo-Polynesian, cabang dari rumpun bahasa Austronesia. Masyarakat Kaur memiliki banyak kesenian tradisional, seperti seni musik, seni tari, seni rupa, pencak silat dan seni sastra. Menurut Badan 
Musyawarah Adat (BMA) Kabupaten Kaur (2014: 164-191), Seni sastra yang ada di Kaur yang terkenal yaitu seni tutur dan berbalas pantun. Seni tutur yang ada di Kaur ada bermacam-macam, seperti guritan, kisah Bujang Remalun, seni tutur meringit, seni tutur ngge'rinik, seni tutur ingit-ingitan, seni tutur betadud dan lain sebagainya.

\section{Metode}

Penelitian ini menggunakan jenis kualitatif dengan metode survei. Dalam penelitian ini data yang ada dikaji dan dideskripsikan sehingga diperoleh gambaran tentang pantun bahasa Kaur sesuai dengan jenis-jenis pantun. Menurut Moleong (2007: 6), penelitian kualitatif adalah penelitian yang bermaksud untuk memahami fenomena tentang apa yang dialami oleh subjek penelitian, misalnya perilaku, persepsi, motivasi, tindakan dan lain sebagainya. Menurut Sukmadinata (2011: 82), survei digunakan untuk mengumpulkan data atau informasi tentang populasi yang besar dengan menggunakan sampel yang relatif kecil.

Subjek dalam penelitian ini, peneliti istilahkan dengan informan karena dalam penelitian pantun-pantun yang tersedia peneliti rekam langsung dari informan.yang menjadi informan kunci adalah ketua Lembaga Adat Kaur (LAKU). Informan selanjutnya adalah orang yang ditunjuk dan ditentukan oleh informan kunci. Orang yang ditunjuk oleh ketua LAKU untuk menjadi informan selanjutnya adalah Bapak Linggang dari desa Pengubaian dan Bapak Abdul Jalil dari desa Gedung Sako II.

Penelitian ini difokuskan untuk mencari data tentang jenis-jenis pantun yang ada di masyarakat Kaur Provinsi Bengkulu. Penelitian ini dilaksanakan di desa Pengubaian, desa Gedung Sako II, dan desa Air Dingin, Kota Bintuhan kecamatan Kaur Selatan, kabupaten Kaur, provinsi Bengkulu.

Pada penelitian kualitataif deskriptif ini instrumen utamanya adalah peneliti sendiri. Kemudian instrumen penelitian dikembangkan secara sederhana untuk dapat melengkapi data yang didapatkan oleh peneliti. Instrumen tersebut yaitulembar wawancara dan dokumentasi.

Teknik pengumpulan data yang digunakan dalam penelitian ini adalah wawancara kepada informan dan dokumentasi. Data yang telah diperoleh dianalisis melalui reduksi data, penyajian (display) data, dan penarikan kesimpulan. Keabsahan data menggunakan perpanjangan pengamatan, peningkatan ketekunan, triangulasi sumber dan member check.Keabsahan data menggunakan perpanjangan pengamatan, peningkatan ketekunan, triangulasi sumber dan member check.

\section{Hasil}

Pantun yang diperoleh dari masyarakat Kaur yang ada di Desa Pengubaian, Desa Gedung Sako II, Desa Air Dingin, Kota Bintuhan, Kecamatan Kaur Selatan, Kabupaten Kaur, Provinsi Bengkulu. Dari beberapa desa tersebut, peneliti mendapatkan hasil wawancara berupa pantun bahasa Kaur, dari Bapak Linggang, Bapak Abdul Jalil, dan Bapak Iswan Marzuki, S.Sos. Dari 
hasil wawancara terkumpul lima puluh dua pantun. Berikut ini disimpulkan hasil pantun yang diperoleh dari masyarakat Kaur:

1. Pantun yang ada di masyarakat KaurDesa Pengubaian oleh Bapak Linggang.

Berdasarkan hasil wawancara Bapak Linggang menyatakan bahwa, dalam masyarakat Kaur budaya berpantun sudah hampir hilang karena sudah jarang digunakan, tidak dikembangkan dan tidak dilestarikan. Pantun dahulunya diturunkan secara turun temurun oleh orang tua kepada anakanaknya. Namun sekarang ini, generasi muda tidak lagi tertarik untuk mempelajari pantun. Pantun bahasa Kaur biasanya digunakan pada acara pernikahan, acara adat, dan perkenalan muda-mudi.

Adapun kumpulan pantun bahasa Kaur yang diperoleh dari Bapak Linggang terdapat empat belas pantun.

2. Pantun yang ada di masyarakat Kaur Desa Gedung Sako II oleh Bapak Abdul Jalil.

Berdasarkan hasil wawancara Bapak Abdul Jalil menyatakan bahwa, perkembangan pantun bahasa Kaur dalam masyarakat Kaur sekarang ini sudah punah. Tidak ada lagi masyarakat yang menggunakan pantun dalam kehidupan sehari-hari maupun acara-acara tertentu. Pantun bahasa Kaur dahulunya memang diturunkan secara turun temurun karena dahulu memang ada grup kesenian yang biasa menampilkan kesenian adat. Dahulu pantun bahasa Kaur digunakan pada acara pernikahan dan perkenalan muda-mudi.

Adapun kumpulan pantun bahasa Kaur yang diperoleh dari Bapak Abdul Jalil terdapat delapan belas pantun.

3. Pantun yang ada di masyarakat Kaur Desa Air Dingin oleh Bapak Iswan Marzuki, S.Sos.

Berdasarkan hasil wawancara Bapak Iswan Marzuki menyatakan bahwa, dalam masyarakat Kaur pantun tidak lagi digunakan. Dahulu pantun digunakan pada setiap acara pernikahan dan digunakan saat muda-mudi berpacaran. Pada saat berpacaran pantun bahasa Kaur digunakan oleh sepasang muda-mudi sebagai sarana berkomunikasi. Pantun memiliki fungsi sebagai sarana mengungkapkan isi hati seseorang kepada orang yang dituju. Selain itu juga bisa sebagai nasehat orang tua kepada anaknya. Pantun bahasa Kaur sama dengan pantun lainnya, perbedaannya hanya pada bahasa yang digunakan.

Adapun kumpulan pantun bahasa Kaur yang diperoleh dari Bapak Iswan Marzuki, S.Sos., terdapat dua puluh pantun.

4. Identifikasi pantun bahasa Kaur seseuai dengan jenis-jenis pantun di masyarakat Kaur di Desa Pengubaian, Desa Gedung Sako II, dan Desa Air Dingin, Kota Bintuhan, Kecamatan Kaur Selatan, Kabupaten Kaur, Provinsi Bengkulu.

Berdasarkan hasil identifikasi diketahui bahwa pantun bahasa Kaur yang diperoleh berjumlah lima puluh dua pantun. jenis-jenis pantun diperoleh, yaitu satu pantun teka-teki, sembilan pantun nasihat, delapan pantun kasih sayang, tiga pantun semangat, dua pantun adat, tiga pantun agama, delapan 
pantun jenaka, sebelas pantun kiasan, enam pantun percintaan dan satu pantun peribahasa.

\section{Pembahasan}

Pantun bahasa Kaur harus tetap dilestarikan, oleh karena itu untuk menambah pengetahuan para generasi muda. Peneliti akan mengelompokkan pantun bahasa Kaur yang di dapat dalam masyarakat Kaur berdasarkan jenis-jenisnya. Pantun ini dikelompokkan ke dalam pantun teka-teki, pantun nasihat, pantun kasih sayang, pantun semangat, pantun adat, pantun agama, pantun jenaka, pantun kiasan, pantun percintaan dan pantun peribahasa.

1. Identifikasi pantun bahasa Kaur sesuai dengan jenis-jenis pantun di masyarakat Kaur di Desa Pengubaian, Desa Gedung Sako II, dan Desa Air Dingin, Kota Bintuhan, Kecamatan Kaur Selatan, Kabupaten Kaur, Provinsi Bengkulu.

\section{a. Jenis Pantun Teka-Teki}

Dari hasil identifikasi terdapat satu pantun teka-teki. Disebut pantun tekateki karena pada dua baris terakhir berbentuk pertanyaan. Hal tersebut sesuai dengan pendapat Wahyuni (2014: 152), bahwa pantun teka-teki adalah jenis pantun yang berbentuk pertanyaan yang biasa digunakan untuk mendidik dan melatih kemampuan anak dalam berpikir mencari jawaban dari pertanyaan yang terkandung di dalam pantun tersebut.

\section{b. Jenis Pantun Nasihat}

Dari hasil identifikasi terdapat sembilan pantun nasihat. Disebut pantun nasihat karena memberikan nasihat kepada orang lain dengan tujuan yang baik. Hal tersebut di atas sesuai dengan pendapat Wahyuni (2014: 155), bahwa pantun nasihat adalah jenis pantun lama yang berisi nasihat dengan tujuan untuk mengajak kebaikan atau mengajak untuk menjadi lebih baik lagi dalam menjalani hidup.

\section{c. Jenis Pantun Kasih Sayang}

Dari hasil identifikasi terdapat delapan pantun kasih sayang. Disebut pantun kasih sayang karena menggambarkan tentang perasaan kasih dan sayang kepada orang lain. Menurut Santoso (2013: 13), bahwa pantun juga digunakan untuk mengungkapkan perasaan kasih sayang dan cinta.

\section{d. Jenis Pantun Semangat}

Dari hasil identifikasi terdapat tiga pantun semangat. Disebut pantun semangat karena memberikan semangat kepada diri sendiri maupun orang lain yang mendengarnya. Sesuai dengan pendapat Wahyuni (2014: 159), pantun semangat adalah jenis pantun lama yang berisi kata-kata penggugah atau pembangkit semangat.

\section{e. Jenis Pantun Adat}

Dari hasil identifikasi terdapat dua pantun adat. Disebut pantun adat karena memberikan pesan dan ajaran kepada orang lain agar tetap melestarikan adat yang ada. Menurut Ganie (2015: 36), pantun adat berfungsi sebagai nasihat yang berhubungan adat istiadat yang berlaku. 


\section{f. Jenis Pantun Agama}

Dari hasil identifikasi terdapat tiga pantun agama. Disebut pantun agama karena memberikan pengetahuan tentang ajaran agama.sesuai dengan pendapat Wahyuni (2014: 164), bahwa pantun agama adalah jenis pantun lama yang berisi pengajaran tentang segala hal yang berhubungan dengan agama.

\section{g. Jenis Pantun Jenaka}

Dari hasil identifikasi terdapat delapan pantun jenaka. Disebut pantun jenaka karena lucu dan orang yang mendengarnya menjadi senang dan terhibur. Menurut Wahyuni (2014: 164), bahwa pantun jenaka adalah jenis pantun lama yang ditunjukkan untuk menghibur hati orang banyak.

\section{h. Jenis Pantun Kiasan}

Dari hasil identifikasi terdapat sebelas pantun kiasan. Disebut pantun kiasan karena menggunakan kata-kata kiasan untuk menambah kesan indah dalam pengucapan. . Sesuai dengan pendapat Wahyuni (2014: 168), bahwa pantun kiasan adalah jenis pantun lama yang menggunakan katakata kiasan.

\section{i. Jenis Pantun Percintaan}

Dari hasil identifikasi terdapat enam pantun percintaan. Disebut pantun percintaan karena mengungkapkan rasa cinta terhadap seseorang.Menurut Wahyuni (2014: 170), bahwa pantun percintaan adalah jenis pantun lama yang isinya menggambarkan tentang perasaan cinta dan segala suka dukanya.

\section{j. Jenis Pantun Peribahasa}

Dari hasil identifikasi terdapat satu pantun peribahasa. Disebut pantun peribahasa karena dalam mengungkapkan sesuatu dengan menggunakan perumpamaan atau pun perbandingan.Menurut Wahyuni (2014: 172), bahwa pantun peribahasa adalah jenis pantun lama berisi kalimat-kalimat peribahasa yang di dalamnya terdapat perbandingan, perumpamaan, nasihat, prinsip hidup, atau aturan tingkah laku.

2. Identifikasi Pantun bahasa Kaur sesuai dengan Ciri-ciri Pantun.

Secara keseluruhan pantun yang diperoleh peneliti dari informan sesuai dengan ciri-ciri pantun yang ada yaitu, terdiri dari empat baris dan bersajak a-b-a-b. Sesuai dengan pendapatWahyuni (2014: 139-140), bahwa pantun terdiri atas empat baris, di mana dua baris pertama merupakan sampiran dan dua baris kedua merupakan isi, bersajak a-b-a-b dan tidak boleh a-a-a-a atau a-a-b-b, jumlah kata tiap baris terdiri dari 8-12 suku kata.

3. Identifikasi Makna Pantun Sesuai dengan Jenis-Jenis Pantun.

Pantun merupakan sastra lama yang bisa digunakan untuk anak-anak, remaja dan orang tua. Jenis-jenis pantun yaitu pantun teka-teki, pantun nasihat, pantun kasih sayang, pantun semangat, pantun adat, pantun agama, pantun jenaka, pantun kiasan, pantun percintaan dan pantun peribahasa. Setiap pantun yang diciptakan memiliki makna tersendiri sesuai 
dengan jenisnya. Makna pantun adalah pesan yang terkandung dalam pantun yang ingin disampaikan oleh penciptanya.

\section{Kesimpulan}

Berdasarkan hasil penelitian dan pembahasan tentang identifikasi pantun bahasa Kaur Desa Pengubaian, Desa Gedung Sako II, dan Desa Air Dingin Kota Bintuhan, kecamatan Kaur Selatan, Kabupaten Kaur, Provinsi Bengkulu sesuai dengan jenis-jenis pantun dapat disimpulkan bahwa: (1) Jumlah pantun yang terkumpul dari informan sebanyak lima puluh dua pantun bahasa Kaur. Empat belas pantun dari desa Pengubaian, delapan belas pantun dari desa Gedung Sako II dan dua puluh pantun dari desa Air Dingin. (2) Jenis-jenis pantun dalam bahasa Kaur teridentifikasi sepuluh jenis pantun dari sepuluh jenis pantun yang ada. Berdasarkan jenis-jenis pantun yaitu pantun teka-teki, pantun nasihat, pantun kasih sayang, pantun semangat, pantun adat, pantun agama, pantun jenaka, pantun kiasan, pantun percintaan, dan pantun peribahasa. (3) Jumlah pantun bahasa Kaur berdasarkan jenis-jenis terdapat satu pantun teka-teki, sembilan pantun nasihat, delapan pantun kasih sayang, tiga pantun semangat, dua pantun adat, tiga pantun agama, tiga pantun jenaka, sebelas pantun kiasan, enam pantun percintaan dan satu pantun peribahasa.

\section{Saran}

1. Masyarakat yang masih mengetahui pantun bahasa Kaur, khususnya orang-orang tua, sudah banyak yang lupa karena tidak ada lagi kegiatan berpantun. Sebaiknya kegiatan berpantun dikembangkan dalam masyarakat dan didokumentasikan agar diketahui generasi penerus.

2. Sebaiknya Pantun bahasa Kaur dapat dikembangkan dan dipelajari di sekolah-sekolah sehingga dapat memberi pengetahuan dan menumbuhkan minat pada generasi muda untuk mempelajari pantun bahasa Kaur.

3. Bagi peneliti selanjutnya agar dapat mengetahui sastra daerah khusunya pantun bahasa Kaur secara lebih luas agar dapat mengumpulkan pantun bahasa Kaur lebih banyak lagi sehingga pantun bahasa Kaur dapat dilestarikan.

\section{Referensi}

Badan Musyawarah Adat (BMA) Kabupaten Kaur. 2014. Khazanah Budaya Kaur. Yoyakarta: LP2B (Lembaga Pengkajian Pembangunan Bangsa).

Fatimah, Riska Friolita. Analisis Kemampuan Siswa dalam Menulis Pantun pada Mata Pelajaran Bahasa IndonesiaKelas IV a Sdn 17 Kota Bengkulu. Penelitian FKIP Unib.

Ganie, Tajuddin Noor. 2015. Buku Induk Bahasa Indonesia. Yogyakarta: Araska.

Herimanto., \& Winarno. 2014. Ilmu Sosial \& Budaya Dasar. Jakarta Timur: Bumi Aksara. 
Moleong, LJ. 2007. Metodologi Penelitian Kualitatif. Bandung: Remaja Rosdakarya.

Purwandari, Retno. 2015. Buku Pintar Bahasa Indonesia. Yogyakarta: Istana Media.

Santoso, Joko. 2013. Pantun Puisi Lama Melayu dan Peribahasa Indonesia. Yogyakarta: Araska.

Sukmadinata, Nana Syaodih. 2011. Metode Penelitian Pendidikan. Bandung: PT Remaja Rosdakarya.

Wahyuni, Ristri. 2014. Kitab Lengkap Puisi, Prosa, dan Pantun Lama. Yogyakarta: Saufa. 